Article

\title{
Advancement of Fluorescent and Structural Properties of Bovine Serum Albumin-Gold Bioconjugates in Normal and Heavy Water with $\mathrm{pH}$ Conditioning and Ageing
}

\author{
Bence Fehér ${ }^{1,2}$, Judith Mihály ${ }^{1}$, Attila Demeter ${ }^{1, *}$, László Almásy ${ }^{2} \mathbb{D}$, András Wacha ${ }^{1}$, Zoltán Varga ${ }^{1} \mathbb{D}$, \\ Imre Varga ${ }^{3}$, Jan Skov Pedersen ${ }^{4}$ and Attila Bóta ${ }^{1, * \mathbb{D}}$
}

\section{check for}

updates

Citation: Fehér, B.; Mihály, J.;

Demeter, A.; Almásy, L.; Wacha, A.;

Varga, Z.; Varga, I.; Pedersen, J.S.;

Bóta, A. Advancement of Fluorescent and Structural Properties of Bovine

Serum Albumin-Gold Bioconjugates

in Normal and Heavy Water with $\mathrm{pH}$

Conditioning and Ageing.

Nanomaterials 2022, 12, 390. https://

doi.org/10.3390/nano12030390

Academic Editor: Rodolphe Antoine

Received: 23 December 2021

Accepted: 20 January 2022

Published: 25 January 2022

Publisher's Note: MDPI stays neutral with regard to jurisdictional claims in published maps and institutional affiliations.

Copyright: (C) 2022 by the authors. Licensee MDPI, Basel, Switzerland. This article is an open access article distributed under the terms and conditions of the Creative Commons Attribution (CC BY) license (https:// creativecommons.org/licenses/by/ $4.0 /)$.
1 Research Centre for Natural Sciences, Institute of Materials and Environmental Chemistry, Magyar Tudósok Körútja 2, 1117 Budapest, Hungary; feher.bence@ek-cer.hu (B.F.); mihaly.judith@ttk.hu (J.M.); wacha.andras@ttk.hu (A.W.); varga.zoltan@ttk.hu (Z.V.)

2 Neutron Spectroscopy Department, Centre for Energy Research, Konkoly-Thege M. út 29-33, 1121 Budapest, Hungary; almasy.laszlo@ek-cer.hu

3 Institute of Chemistry, Eötvös Loránd University (ELTE), Pázmány Péter sétány 1/A, 1117 Budapest, Hungary; varga.imre@ttk.elte.hu

4 Department of Chemistry and Interdisciplinary Nanoscience Center (iNANO), Aarhus University, Gustav Wieds Vej 14, 8000 Aarhus C, Denmark; jsp@chem.au.dk

* Correspondence: demeter.attila@ttk.hu (A.D.); bota.attila@ttk.hu (A.B.)

\begin{abstract}
The red-emitting fluorescent properties of bovine serum albumin (BSA)-gold conjugates are commonly attributed to gold nanoclusters formed by metallic and ionized gold atoms, stabilized by the protein. Others argue that red fluorescence originates from gold cation-protein complexes instead, not gold nanoclusters. Our fluorescence and infrared spectroscopy, neutron, and X-ray small-angle scattering measurements show that the fluorescence and structural behavior of BSA-Au conjugates are different in normal and heavy water, strengthening the argument for the existence of loose ionic gold-protein complexes. The quantum yield for red-emitting luminescence is higher in heavy water $(3.5 \%)$ than normal water $(2.4 \%)$, emphasizing the impact of hydration effects. Changes in red luminescence are associated with the perturbations of BSA conformations and alterations to interatomic gold-sulfur and gold-oxygen interactions. The relative alignment of domains I and II, II and III, III and IV of BSA, determined from small-angle scattering measurements, indicate a loose ("expanded-like") structure at $\mathrm{pH} 12$ (pD 12); by contrast, at $\mathrm{pH} 7$ (pD 7), a more regular formation appears with an increased distance between the I and II domains, suggesting the localization of gold atoms in these regions.
\end{abstract}

Keywords: red-fluorescence; protein-gold conjugates; change in protein conformation; fluorescence; small angle $\mathrm{X}$-ray scattering; small angle neutron scattering

\section{Introduction}

Biocompatible red fluorescent BSA-gold conjugates offer favorable biological applications because their red fluorescence significantly differs from tissue materials' blue or green auto-fluorescence [1]. An elegant and simple one-pot aqueous synthesis of fluorescent bovine serum albumin-gold (BSA-Au) complexes was first described by Xie et al., a pioneering work in the field [2]. In the presence of hydrogen tetrachloroaurate $\left(\mathrm{HAuCl}_{4}\right)$, the interaction between the BSA and gold salt is driven in the alkaline medium ( $\mathrm{pH} 12)$, resulting in a significant red luminescence at around $670 \mathrm{~nm}$, which slightly increases when the system neutralizes. Despite intensive studies, there is no consensus about the origin of red emittance. The question is still open-what are the red-emitting parts of the BSA-Au conjugates, and what do they look like? After the inventors, it has been widely accepted that the fluorescent properties result from gold nanoclusters composed of 25 atoms and stabilized by BSA, which were already known to show red fluorescence [2]. It was reported 
that nanoclusters with 25 atoms have a core-shell structure consisting of an icosahedral core of 12-13 metallic gold atoms surrounded by six $\mathrm{Au}_{2}(\mathrm{SR})_{3}$ staples covalently bonded to a BSA molecule via the sulfuric groups [2-7]. This structural explanation was deduced from matrix-assisted laser desorption-ionization time-of-flight (MALDI-TOF) and X-ray photoelectron spectroscopy (XPS) methods where, unfortunately, water, as a characteristic structural element, is expelled from the system. Other methods, such as Nuclear Magnetic Resonance (NMR), infrared spectroscopy (IR), and small-angle X-ray scattering (SAXS), show that BSA is a dynamic, "living" system assuming different conformations reversibly in an extensive $\mathrm{pH}$ range. The aqueous solution of BSA has five different conformations as the function of $\mathrm{pH}$ : expanded, fast, normal, basic, and aged forms [8]. In the presence of $\mathrm{HAuCl}_{4}, \mathrm{pH}$ plays an important role. At $\mathrm{pH}=12$, the BSA-molecules become negatively charged and undergo conformational changes while attracting Au(III) ions, predominantly in regions rich in reducing tyrosine and histidine residues. The key to understanding the red emission's origin is clarifying the interactions between the neighboring Au atoms or ions [9]. Dixon and Egussa observed that these gold cation-protein complexes caused their red emissions after a further reduction process using sodium borohydride, whereby metal nanoparticles were formed. Therefore, they supposed that the BSA-gold compounds, described by Xie et al. as $\mathrm{Au}_{25}$ nanoclusters, were BSA-cationic gold complexes [10]. Moreover, they observed that conformational changes of BSA influence the fluorescence behavior of complexes. They also suggested that the origin of the red fluorescence involves an energy transfer among chromophores formed by the gold and protein residues. The same authors concluded that cysteine, 34 of which form disulfide bonds in BSA, is the binding site of $\mathrm{Au}(\mathrm{III})$ but not the location of the red-emitting fluorophore. Recently, the same research group identified the $\mathrm{Au}(\mathrm{III})$ binding domain of BSA and localized the origin of red fluorescence within the N-terminal domain using limited proteolysis and molecular cloning techniques based on luminescence measurements [11]. However, the changes and evolution in fluorescent properties are primarily connected to global changes in BSA-gold complexes dependent on the $\mathrm{pH}$ value and accompanied by significant structural changes on the atomic level as observed by small-angle X-ray scattering and infrared spectroscopy [12]. The conformation of BSA is not reversible after a neutral-alkali-neutral cycle, and its consequences in fluorescence can be observed. The irreversibility is more pronounced in the presence of $\mathrm{Au}(\mathrm{III})$ ions, indicating the importance of hydration effects. Besides the advantages of heavy water use in the neutron scattering techniques, it provides a solvent milieu different from normal water, enabling the observation of hydration-induced structural and conformational changes. It is well-known that the deuterium-hydrogen isotope effect causes significant changes in the folding-unfolding processes of proteins $[13,14]$. In this work, we show that heavy water, compared to normal water, induces more decided effects in both global and fine structures and that these changes bring a significantly increased red fluorescence than that observed in normal water.

\section{Materials and Methods}

\subsection{Materials}

Bovine serum albumin (BSA, $>99 \%$ ) and $\mathrm{HAuCl}_{4} \cdot 3 \mathrm{H}_{2} \mathrm{O}(99.99 \%)$ were purchased from Sigma-Aldrich (Sigma-Aldrich, St. Louis, MO, USA) and used as received. The $\mathrm{pH}$ of the solutions was adjusted with $\mathrm{HCl}$ (Sigma-Aldrich, St. Louis, MO, USA) and $\mathrm{NaOH}$ (Sigma-Aldrich, St. Louis, MO, USA). All solutions were prepared in ultra-pure Milli-Q water (total organic content $\leq 4 \mathrm{ppb}$; resistivity $\geq 18 \mathrm{M} \Omega \mathrm{cm}$ ) and heavy water (deuterium oxid for NMR, 99.8\% D) purchased from Acros Organics (Morris Plains, NJ, USA).

\subsection{Sample Preparation}

A total of $1.67 \mathrm{w} \% \mathrm{BSA}-\mathrm{Au}(\mathrm{III})$ stock solutions in normal and heavy water were prepared by mixing $2.5 \mathrm{w} \% \mathrm{BSA}$ solutions with $10 \mathrm{mM} \mathrm{HAuCl}_{4}$ solutions in 2:1 volume ratio (corresponding with 13:1 ion-protein molar ratio) at moderate stirring rate (600 rpm). After mixing, the $\mathrm{pH}$ of the stock solutions was set to 12 ( $\mathrm{pD}$ to $\approx 11.6$ ) by dilute $\mathrm{NaOH}$ 
solutions ( $1 \mathrm{M}$, both in normal and heavy water) under stirring. After storage at room temperature for two days, the BSA-Au(III) systems were heat-treated at $37{ }^{\circ} \mathrm{C}$ for $2 \mathrm{~h}$, then neutralized and stored at room temperature. The beginning and transitional states at $\mathrm{pH}=12(\mathrm{pD} \approx 11.6)$ and neutral $\mathrm{pH}(\mathrm{pD})$ were measured with fluorescence, infrared spectroscopy, and DLS methods. The same preparation protocol was used for the X-ray and neutron scattering methods.

\subsection{Fluorescence Spectroscopy}

The luminescence of the BSA-Au conjugates was measured using a Jasco FP8500 spectrofluorometer (Jasco International Co., Ltd., Tokyo, Japan) at $25^{\circ} \mathrm{C}$ in MQ water and $360 \pm 5 \mathrm{~nm}$ excitation in the 380-750 $\mathrm{nm}$ range. The spectral correction function was assessed by the Maroncelly dye setup [15]. The luminescence quantum yields were determined relative to the 0.546 value of quinine sulfate in $1 \mathrm{~N}$ sulfuric acid [16]. It must be noted that considering the low sensitivity of the fluorometer in the red region, the red band's maxima, and the corresponding fluorescence yields, may be slightly underestimated. The air-saturated samples were measured in a $3 \mathrm{~mm} \times 3 \mathrm{~mm} \times 40 \mathrm{~mm}$ quartz cuvette with an optical density at the excitation wavelength around 1.4 .

\subsection{Infrared Spectroscopy}

Attenuated total reflection-Fourier transform infrared (ATR-FTIR) spectroscopy measurements were conducted using a Varian 2000 FTIR Scimitar spectrometer (Varian Inc., Palo Alto, CA, USA) fitted with a liquid nitrogen-cooled mercury cadmium telluride (MCT) detector and a 'Golden Gate' single reflection diamond ATR accessory (Specac Ltd., Orpington, UK). A sample amount of $5 \mu \mathrm{L}$ was dropped onto the diamond ATR surface, and the dry film spectrum was collected (at $2 \mathrm{~cm}^{-1}$ resolution and 64 scans) after the slow evaporation of the solvent under ambient conditions. Each data acquisition was followed by ATR correction. Spectral deconvolution was performed using the GRAMS/AI (7.02) spectroscopy software (Thermo Galactic, Walthman, MA, USA). Band positions for curve fitting were established using the second derivative and were fixed during the fitting procedure. Band shapes were approximated by Lorentzian functions. The intensities and the bandwidth of each component were allowed to vary until the minimal $\chi^{2}$ parameter was reached. After the fitting procedure, the relative contribution of a particular band component was calculated from the integrated areas of the individual components [17].

\subsection{Dynamic Light Scattering}

Dynamic light scattering (DLS) of the samples was measured at $20{ }^{\circ} \mathrm{C}$ using a W130i dynamic light scattering device (Avid Nano Ltd., High Wycombe, UK) with a diode laser $(660 \mathrm{~nm})$ and a photodiode detector. Eppendorf disposable cuvettes (50-2000 $\mu \mathrm{L}$, UVette routine pack, Vienna, Austria) with a $1 \mathrm{~cm}$ path-length were used [18]. Samples containing approx. $10 \mu \mathrm{M}$ BSA were measured in a final volume of $80 \mu \mathrm{L}$ in MQ water. We measured the time-dependent autocorrelation function for $10 \mathrm{~s}$, repeated it ten times, and reported the average distributions. A data analysis yielding the mean hydrodynamic diameter $\left(D_{h}\right)$ and polydispersity (\%) was performed with iSize 3.0 software supplied with the device.

\subsection{Small-Angle X-ray Scattering}

Small-angle $X$-ray scattering measurements were performed using CREDO, an inhouse transmission geometry setup $[19,20]$. Thin-walled quartz capillaries with a $1.5 \mathrm{~mm}$ average outer diameter were filled with samples. After proper sealing, these were placed into a temperature-controlled aluminum block inserted into the vacuum space of the sample chamber. Measurements were recorded using monochromatized and collimated $\mathrm{Cu}$ $\mathrm{K} \alpha$ radiation (1.542 $\AA$ wavelength); the scattering pattern was recorded in the range of $0.02-0.5 \AA^{-1}$ in terms of the scattering variable/momentum transfer $(q=(4 \pi / \lambda) \sin \theta$, where $2 \theta$ is the scattering angle, and $\lambda$ is the $X$-ray wavelength). The total measurement time was $7.5 \mathrm{~h}$ for each sample. In order to assess sample and instrument stability dur- 
ing the experiment, the exposures were recorded in 5-min units, with frequent sample change and reference measurements. These individual exposures were corrected for beam flux, geometric effects, sample self-absorption, and instrumental background, as well as calibrated into physical units of momentum transfer and volume-normalized differential scattering cross-sections (absolute intensity, $\mathrm{cm}^{-1} \times \mathrm{sr}^{-1}$ ). The corrected and calibrated 5-min scattering patterns were azimuthally averaged to yield a single one-dimensional scattering curve for each sample.

\subsection{Small-Angle Neutron Scattering}

Small-angle neutron scattering measurements were recorded with the "Yellow Submarine" diffractometer operating at the Budapest Neutron Centre [21,22]. Two sample-detector distances of 1.2 and $5.3 \mathrm{~m}$ and a quasi-monochromatic neutron wavelength of $0.42 \mathrm{~nm}$ allowed us to cover a $q$-range of $0.01-0.5 \AA^{-1}$. Liquid samples were filled in quartz cells with a $2 \mathrm{~mm}$ path length, and the measurements were recorded at $25^{\circ} \mathrm{C}$. The raw data were corrected for sample transmission, cell and room background scattering, and the absolute intensity scale was calibrated by the level of incoherent scattering from an $\mathrm{H}_{2} \mathrm{O}$ sample.

\section{Results and Discussion}

\subsection{Red Emission Characterized with Fluorescence Spectroscopy}

The luminescence spectra of BSA-Au conjugates were studied in normal and heavy water solutions. Two hours after mixing the two basic (BSA and $\mathrm{HAuCl}_{4}$ ) solutions (at $\mathrm{pH}=12$ and $\mathrm{pD} \approx 11.6$ ), luminescence appears in both normal and heavy water systems. The emission, however, is very low in terms of quantum yield, and the moderate deviation of the emission spectra indicates different characteristics for the two systems, as shown in Figure 1A. Indeed, a simple visual observation of the systems, with a blue laser pointer, already indicates the rapid evolution of red emission in $\mathrm{H}_{2} \mathrm{O}$, whereas the amount of time required for $\mathrm{D}_{2} \mathrm{O}$ is more prolonged, at least one day. Blue luminescence (centered at $440 \mathrm{~nm}$ ) appears in both systems but is relatively larger in normal water. Two days after setting the $\mathrm{pH}(\mathrm{pD})$ to neutral (performed two days after the preparation at alkaline conditions), the systems show drastic changes in their luminescence spectra (Figure 1B). The red emission becomes intensive and turns into the prevalent range. The previously observed blue fluorescence is also present but is not the characteristic feature anymore. Interestingly, the red emittance of the $\mathrm{D}_{2} \mathrm{O}$ system is significantly higher than $\mathrm{H}_{2} \mathrm{O}$. These differences reflect in the fluorescence quantum yield values, which are 0.035 in the presence of $\mathrm{D}_{2} \mathrm{O}$ and 0.024 in the $\mathrm{H}_{2} \mathrm{O}$ system.

All spectra in Figure 1 can be described by three distinct bands, with the maxima slightly blue-shifted when the deuterated solvent was used. One may conclude that at $\mathrm{pH}(\mathrm{pD}) \approx 7$, after longer conditioning the samples at $\mathrm{pH}(\mathrm{pD}) \approx 12$ (shown in Figure $1 \mathrm{~B}$ ), the fluorescence yields increase by a factor of ten, while the red emission bands become much more intensive. The maximum of the lowest energy band is shifted to red with conditioning, especially for $\mathrm{D}_{2} \mathrm{O}$ (requiring longer relaxation time). In the case of the conditioned samples, the deuteration of the solvent results in a 50\% increase in fluorescence yield, partly resulting from the broadening of the red band. The concomitant blue and red luminescence intensities were followed through several days. The ageing time-course of the red luminescence showed drastically different characters in the two aqueous systems. The red luminescence showed high intensity in normal water after $2 \mathrm{~d}$; then, the values reduced significantly. However, in $\mathrm{D}_{2} \mathrm{O}$, the increase in red luminescence took several days, indicating a longer formation time for the more effective red emission with the concomitant configuration of BSA-Au conjugates. 

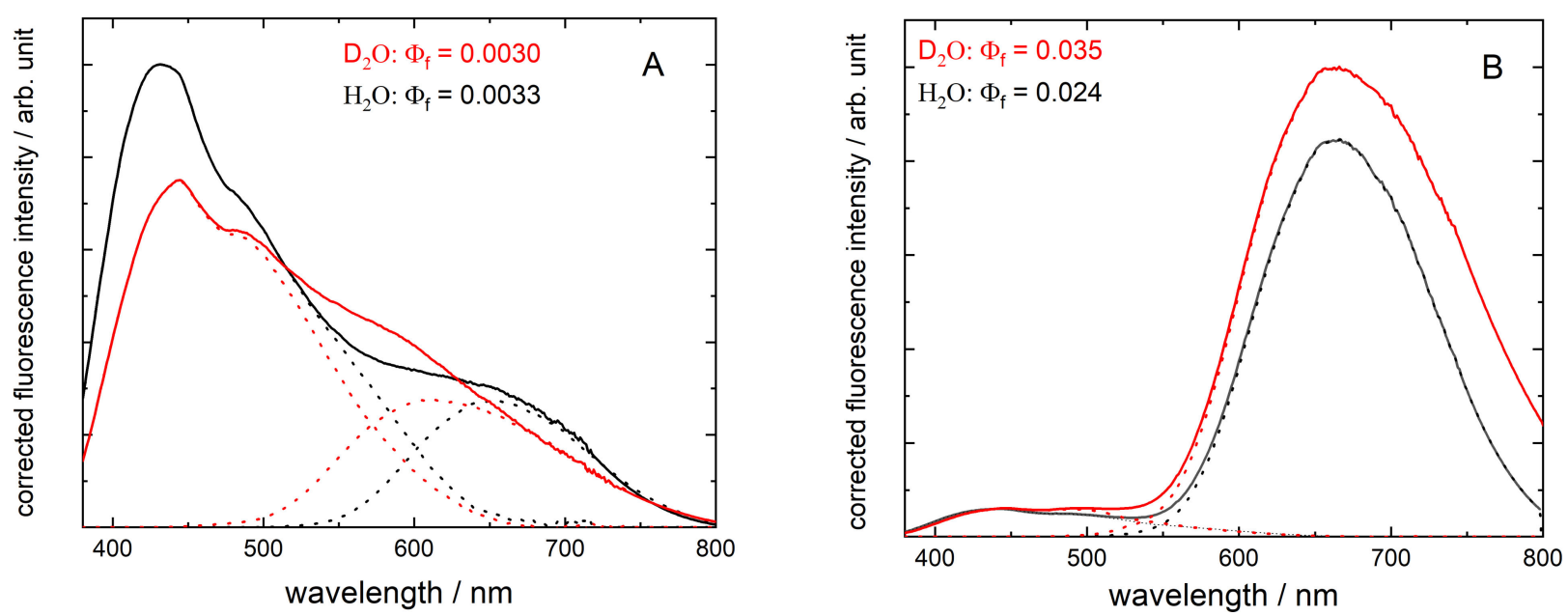

Figure 1. Corrected fluorescence spectra of BSA-Au conjugates in normal (black lines) and heavy water (red lines). In (A), the arbitrary intensities are multiplied by a factor of ten, compared with (B), the luminescence was detected just $2 \mathrm{~h}$ after reaching $\mathrm{pH}(\mathrm{pD})=12$, whereas in $(\mathbf{B})$, after conditioning the samples at $\mathrm{pH}(\mathrm{pD})=12$ for $2 \mathrm{~d}$, and subsequently neutralizing to $\mathrm{pH}=7(\mathrm{pD} \approx 7)(2 \mathrm{~d})$. (The dotted lines indicate an approximate resolution of the reddest band and the other two bands together.).

\subsection{Fine Structural Perturbations Observed by Infrared Spectroscopy}

Possible conformational changes of BSA, following preparation steps and luminescence development, were inspected by ATR-FTIR spectroscopy. We focused on the amide I and amide II band regions (from 1750 to $1350 \mathrm{~cm}^{-1}$ ), belonging to the $\mathrm{C}=\mathrm{O}$, and $\mathrm{N}-\mathrm{H}$ and $\mathrm{N}-\mathrm{C}$ vibrations of peptide bonds from protein backbones, respectively, as shown in Figure 2A.
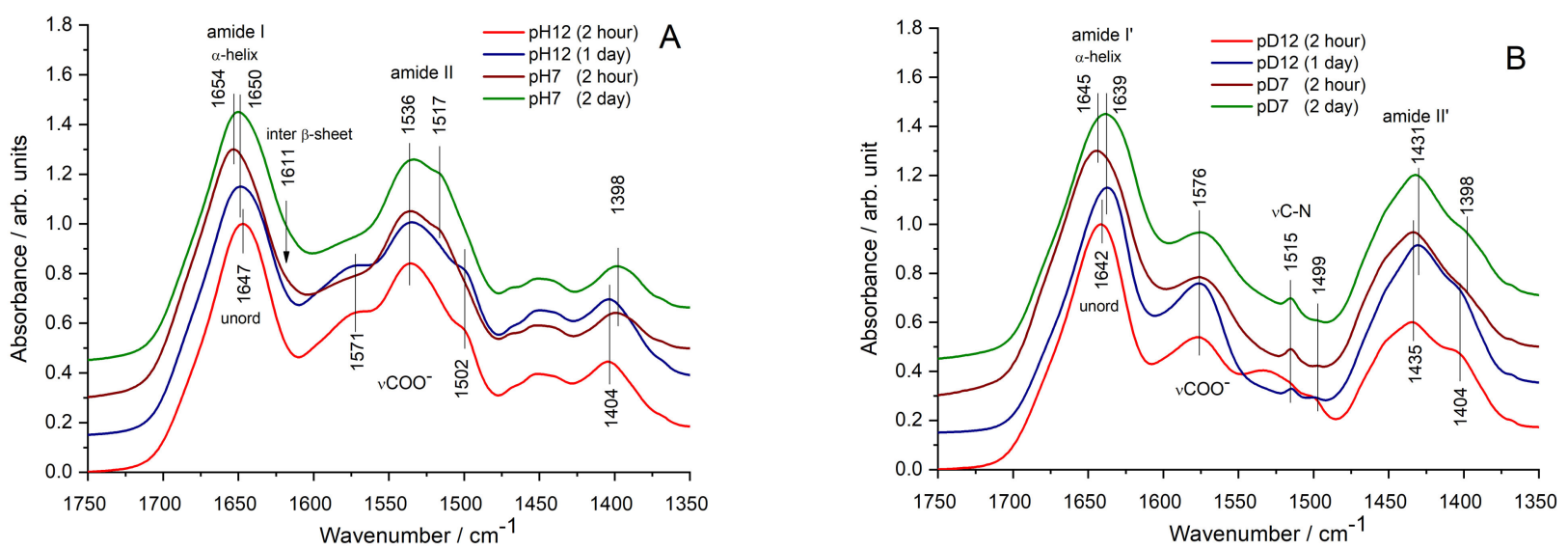

Figure 2. Amide I and amide II regions of IR spectra obtained from BSA-AU bioconjugate samples in $\mathrm{H}_{2} \mathrm{O}(\mathbf{A})$ and in $\mathrm{D}_{2} \mathrm{O}(\mathbf{B})$. Spectra are normalized to the highest amide I peak and shifted vertically for improved visualization.

Amide I, composed mainly from the $\mathrm{C}=\mathrm{O}$ vibration of the peptide bonds, is sensitive to the H-bonding network of the protein backbone. Consequently, by band deconvolution $[23,24]$, the secondary structure of proteins can be deduced (Table 1). At $\mathrm{pH}=12$, the BSA structure in the BSA-Au bioconjugate is dominated by random coils and $\beta$-sheets, resulting in a broad amide I band with a peak at $1647 \mathrm{~cm}^{-1}$. These results align with our previous observation at $\mathrm{pH}=12$, when the BSA backbone became extended with loose unordered parts [12]. The multiple-band structure of amide II also confirms the open, elongated protein geometry with exposed $\mathrm{COO}^{-}$groups of amino acid side chains (affirmed by the shoulders at 1571,1502 $\mathrm{cm}^{-1}$, and the band around $1404 \mathrm{~cm}^{-1}$ ). Compared 
to the spectrum of the native BSA [12], however, the relative increase in intensity suggests that $\mathrm{Au}$ ions may interact with the exposed, negatively charged carboxy groups of the elongated protein.

Table 1. Secondary structure of BSA-Au conjugate system in $\mathrm{H}_{2} \mathrm{O}$ estimated by the deconvolution of amide I IR band (expressed in \%, the peak position of the component bands is provided).

\begin{tabular}{ccccccc}
\hline & $\begin{array}{c}\beta \text {-Turns } \\
\mathbf{1 6 8 7} \mathbf{~ m}^{-\mathbf{1}}\end{array}$ & $\begin{array}{c}\boldsymbol{\alpha} \text {-Helix } \\
\mathbf{1 6 5 6} \mathbf{~ m}^{-\mathbf{1}}\end{array}$ & $\begin{array}{c}\text { Loose } \alpha \text {-Helix } \\
\mathbf{1 6 5 1} \mathbf{~ m}^{-\mathbf{1}}\end{array}$ & $\begin{array}{c}\text { Random Coil } \\
\mathbf{1 6 4 8} \mathbf{~ c m}^{-\mathbf{1}}\end{array}$ & $\begin{array}{c}\beta \text {-Sheet } \\
\mathbf{1 6 3 8} \mathbf{~ c m}^{-\mathbf{1}}\end{array}$ & $\begin{array}{c}\text { Inter. } \beta \text {-Sheet } \\
\mathbf{1 6 1 1} \mathbf{~ m}^{-\mathbf{1}}\end{array}$ \\
\hline pH12 & 17 & - & & 74 & 9 & - \\
pH12 (2 d) & 35 & 23 & - & 42 & - \\
pH7 (2 h) & 32 & 33 & 41 & - & 33 & 2 \\
pH7 (2 d) & 27 & - & 41 & 29 & 3 \\
\hline
\end{tabular}

After $1 \mathrm{~d}$, a slight "reorganization" of protein structure can be observed, reflected by the amide I peak shift toward a higher wavenumber (from 1647 to $1650 \mathrm{~cm}^{-1}$ ). However, more significant spectral changes are witnessed upon adjusting the $\mathrm{pH}$ to neutral $(\mathrm{pH}=7)$. The amide I band peak is shifted toward $1654 \mathrm{~cm}^{-1}$, presuming a dominantly helical structure. The shoulder bands in the amide II region, assigned to $\mathrm{COO}^{-}$groups of the amino acid side-chains also decrease. We assumed that protein refolding in BSA-Au conjugates, forced by $\mathrm{H}$-bonds formation upon $\mathrm{pH}$ adjustment, might lead to the development of $\mathrm{Au}-\mathrm{Au}$ interactions. After $2 \mathrm{~d}$, a "relaxation" occurs in the amide I peak, but no changes occur in the amide II and side-chain band features. A detailed analysis after band deconvolution also revealed the presence of intermolecular $\beta$-sheets suggesting that Au association occurs in the final state at $\mathrm{pH}=7$ (Table 1$)$.

Using $\mathrm{D}_{2} \mathrm{O}$ as a solvent, due to the hydrogen/deuterium exchange, the IR spectra of BSA-Au systems are different (Figure 2B). The amide I band of unordered protein conformations appears at $1642 \mathrm{~cm}^{-1}$. The amide II band (N-H deformation vibration of peptide bonds) at $1538 \mathrm{~cm}^{-1}$ is suppressed, and a new amide II' band (N-D deformation vibration of peptide bonds) at $1431 \mathrm{~cm}^{-1}$ is raised. It is worth noting that the bands of exposed charged carboxylate groups (at 1576 and $1499 \mathrm{~cm}^{-1}$ ) are also observable. After 1 day, another slight 'relaxation' can be noticed; however, now the amide I' peak is shifted in the opposite direction, toward a lower wavenumber. It appears that in $\mathrm{D}_{2} \mathrm{O}$, disordered or sheet-like protein structures are formed in the BSA-Au conjugate. By adjusting the $\mathrm{pH}(\mathrm{pD})$ to 7, the alteration in spectral features resembles the BSA-Au/ $\mathrm{H}_{2} \mathrm{O}$ system with a stronger contribution of helical conformations. After $2 \mathrm{~d}$, however, the sheet-like or disordered structure is favored (Table 2).

Table 2. Secondary structure of BSA-Au conjugate system in $\mathrm{D}_{2} \mathrm{O}$ estimated by deconvolution of amide I IR band (expressed in \%, with the peak position of the component bands).

\begin{tabular}{ccccccc}
\hline & $\begin{array}{c}\beta \text {-Turns } \\
\mathbf{1 6 8 7} \mathbf{~ c m}^{-\mathbf{1}}\end{array}$ & $\begin{array}{c}\boldsymbol{\alpha} \text {-Helix } \\
\mathbf{1 6 5 6} \mathbf{~ m}^{-\mathbf{1}}\end{array}$ & $\begin{array}{c}\text { Loose } \alpha \text {-Helix } \\
\mathbf{1 6 5 1} \mathbf{~ m}^{-\mathbf{1}}\end{array}$ & $\begin{array}{c}\text { Random Coil } \\
\mathbf{1 6 4 8} \mathbf{~ m}^{-\mathbf{1}}\end{array}$ & $\begin{array}{c}\beta \text {-Sheet } \\
\mathbf{1 6 3 8} \mathbf{~ m}^{-\mathbf{1}}\end{array}$ & $\begin{array}{c}\text { Inter. } \beta \text {-Sheet } \\
\mathbf{1 6 1 1} \mathbf{~ c m}^{-\mathbf{1}}\end{array}$ \\
\hline pD12 & 21 & - & - & 70 & - & 9 \\
pD12 (2 d) & 35 & - & - & - & 62 & 3 \\
pD7 (2 h) & 29 & 1 & 15 & - & 70 & - \\
pD7 (2 d) & 34 & & & & 51 & - \\
\hline
\end{tabular}

In conclusion, it seems plausible that in alkaline environments, the initial BSA-Au interaction is also affected by the choice of solvent and influenced by the BSA's geometry. In a neutral state ( $\mathrm{pH}=7$ and at $\mathrm{pD} 7$ ), a helical structure tends to form to different extents, resulting in slightly different protein secondary structures. This finding aligns with the significant fluorescence changes of BSA-Au conjugates. 


\subsection{Conformational Changes of BSA-Au Conjugates Observed by Small-Angle X-ray and Neutron Scattering}

To receive insight into the global structure of the conjugate prepared in $\mathrm{D}_{2} \mathrm{O}$, with special emphasis on the BSA, we performed small-angle X-ray and neutron scattering experiments. The X-ray scattering length density (SLD) is proportional to the atomic number, whereas the neutron SLD depends on the neutron scattering cross-section of nuclei. Thus, SANS and SAXS provide slightly different information on the two systems; however, the scattering is likely dominated by protein scattering in both cases. Due to the lesser amount of gold ions compared with proteins (13:1 Au ion to BSA molar ratio), the scattering contribution of Au was expected to be negligible, even if concentrated in small nanoclusters.

In Figure 3, the one-dimensional SAXS and SANS curves are presented. The radii of gyration were determined by both the Guinier approximation and indirect Fourier transformation (IFT) and are presented in Table $3[25,26]$. The forward scattering was also determined by IFT. The radius of gyration for BSA in $\mathrm{D}_{2} \mathrm{O}$ is in good agreement with the value of BSA in normal water [27]. Adding gold salt did not change this result significantly ( $\mathrm{pD} \sim 12$, SANS result). However, adjusting the $\mathrm{pD}$ to 7 results in an increased radius of gyration around $39 \AA$, which coincides with the literature value for the BSA dimer [27]. SAXS yields slightly larger values than SANS for the same $\mathrm{pD}$ states. The reason for this lies in differences between the $\mathrm{X}$-ray and neutron techniques and the uncertainty of $\mathrm{R}_{\mathrm{G}}$ determination. The forward scattering of samples at $\mathrm{pD} \sim 7$ is approximately double that of pD $\sim 12$ for both SANS and SAXS, as shown in Figure 3 and Table 3 . Since forward scattering is proportional to the molar mass of the scattering objects, we concluded that dimerization occurs during the neutralization because the concentration of the samples is the same. The higher SAXS intensity (compared to SANS) results from the different scattering mechanisms. We noted that dimerization did not occur in normal water, which is a significant difference in the formation of BSA-Au conjugates in the two water systems [12]. Figure 4 presents the Kratky plots of the SAXS curves (taken on $\mathrm{D}_{2} \mathrm{O}$ systems). This representation emphasizes the high- $q$ region of the scattering curves, which is only reliable for SAXS because the incoherent scattering of SANS experiments renders the background subtraction slightly imprecise. The sample curve at $\mathrm{pD} \sim 12$ increases with high $q$, which is characteristic to (at least partially) unfolded proteins. However, at $\mathrm{pD} \sim 7$, the Kratky plot exhibits a maximum at low- $q$ and plateau at high- $q$, indicating that the protein has folded.

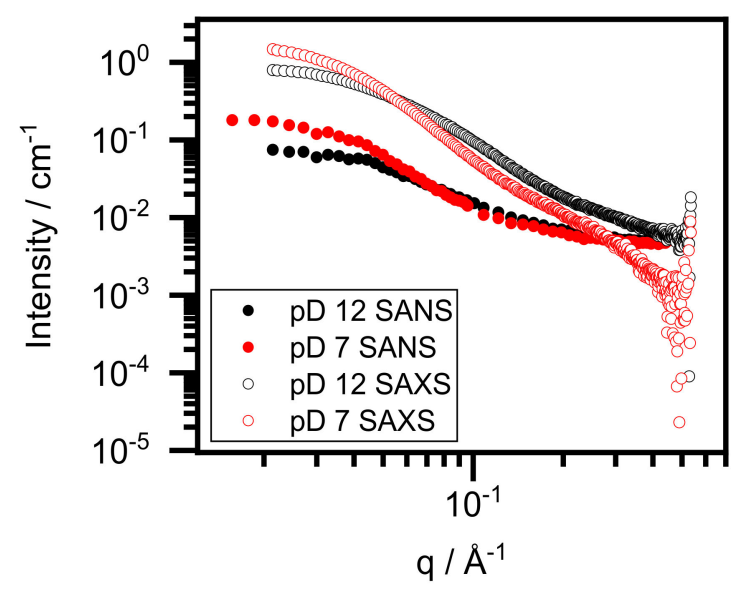

Figure 3. Small-angle $X$-ray and small-angle neutron scattering curves of BSA-Au conjugates at $\mathrm{pD} \sim 12$ and $\mathrm{pD} \sim 7$. 
Table 3. Parameters obtained by the data evaluation of SANS and SAXS curves.

\begin{tabular}{|c|c|c|c|c|c|c|c|c|c|c|}
\hline & \multicolumn{2}{|c|}{ BSA pD7 SANS } & \multicolumn{2}{|c|}{ BSA-Au pD12 SANS } & \multicolumn{2}{|c|}{ BSA-Au pD7 SANS } & \multicolumn{2}{|c|}{ BSA-Au pD12 SAXS } & \multicolumn{2}{|c|}{ BSA-Au pD7 SAXS } \\
\hline $\mathrm{I}(0)\left(\mathrm{cm}^{-1}\right)$ & \multicolumn{2}{|c|}{$0.037 \pm 1 \times 10^{-3}$} & \multicolumn{2}{|c|}{$0.076 \pm 1 \times 10^{-3}$} & \multicolumn{2}{|c|}{$0.200 \pm 4 \times 10^{-3}$} & \multicolumn{2}{|c|}{$0.948 \pm 1 \times 10^{-3}$} & \multicolumn{2}{|c|}{$1.970 \pm 0.026$} \\
\hline RG (̊) Guinier fit & \multicolumn{2}{|c|}{$28.4 \pm 0.9$} & \multicolumn{2}{|c|}{$27.1 \pm 0.1$} & \multicolumn{2}{|c|}{$38.3 \pm 0.4$} & \multicolumn{2}{|c|}{$31.60 \pm 0.06$} & \multicolumn{2}{|c|}{$43.0 \pm 0.390$} \\
\hline RG $(\AA)$ IFT & \multicolumn{2}{|c|}{$29.75 \pm 1.12$} & \multicolumn{2}{|c|}{$28.47 \pm 0.40$} & \multicolumn{2}{|c|}{$39.37 \pm 0.46$} & \multicolumn{2}{|c|}{$33.71 \pm 0.04$} & \multicolumn{2}{|c|}{$44.98 \pm 0.30$} \\
\hline Fitting method & DAMMIF & SASREF & DAMMIF & SASREF & DAMMIF & SASREF & DAMMIF & SASREF & DAMMIF & SASREF \\
\hline$x^{2}$ & 1.11 & 1.09 & 1.09 & 1.95 & 1.63 & 1.04 & 1.95 & 6.56 & 0.73 & 1.46 \\
\hline
\end{tabular}

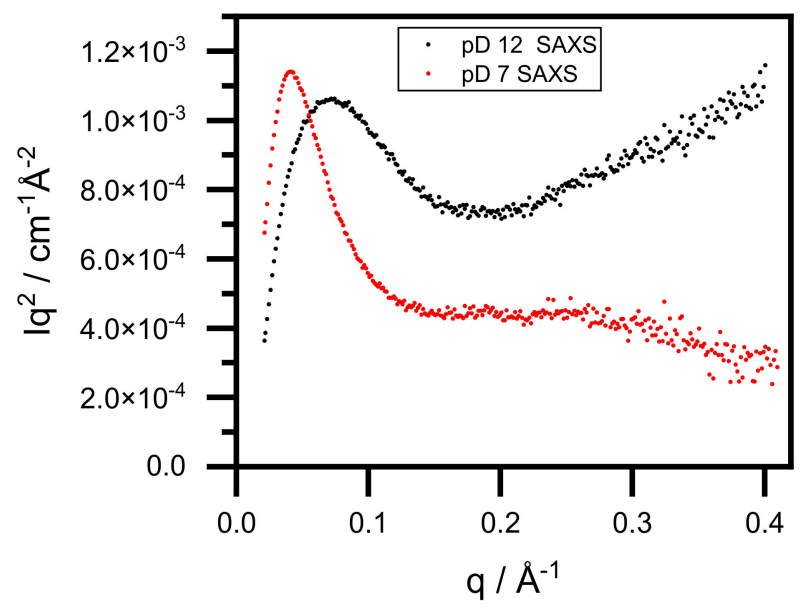

Figure 4. Kratky representation of small-angle X-ray scattering curves of BSA-Au conjugates at $\mathrm{pD} \sim 12$ and $\mathrm{pD} \sim 7$.

To reveal protein structural changes in the complex system caused by $\mathrm{pH}$ variation, we performed ab initio modeling with DAMMIF and rigid-body refinement with SASREF on curves obtained by SAXS and SANS [28,29]. The native BSA structure was grouped into four linked domains (marked by different colors in Figures 5 and 6: domain I: residue 1-147 (blue), domain II: residue 148-300 (magenta), domain III: residue 301-495 (green), and domain IV: residue 496-583 (orange). Ten runs were performed with DAMMIF and SASREF, and the obtained structures were processed by DAMAVER [30]. For samples with $\mathrm{pH}$ (or $\mathrm{pD}$ ) adjusted to 7 and the presumed dimer structures, a P2 symmetry was imposed. Additionally, the dimer structure was also fitted without requiring symmetry, but the fit did not improve significantly. Therefore, we chose to keep the requirement on the P2 symmetry since it decreases the degrees of freedom and yields more robust results.

The scattering curves of SASREF fits are shown along with measured ones in the graphs on the left-hand side of Figure 6, while the corresponding models obtained by both DAMMIF and SASREF on the right-hand side are aligned and overlaid. The resulting structures from the two different simulation methods are in good agreement. As a reference, the BSA in $\mathrm{D}_{2} \mathrm{O}$ without $\mathrm{HAuCl}_{4}$ was also fitted. The structure of $\mathrm{BSA}$ in $\mathrm{D}_{2} \mathrm{O}$ resembles normal water, as observed in our previous work [12]. From the SASREF fits of SANS curves, we concluded that the four-domain structure satisfactorily describes the scattering data $\left(\chi^{2}\right.$ values are presented in Table 3$)$, suggesting that the conformation of the protein is not seriously affected by the gold salt. However, a relative change in the domains' arrangement can be observed by adding $\mathrm{HAuCl}_{4}$ and increasing the $\mathrm{pD}$ to $\sim 12$. Adjusting the $\mathrm{pD}$ to $\sim 7$ allows for further change in the domains' arrangement besides dimerization. To receive insight into the motion of domains, we defined the 'main axis' of each domain by the first and last amino acid of the domain. Then, the angles of two adjacent domains were calculated according to their main axis for each sample in all 10 SASREF simulation runs, averaged, and normalized to the appropriate angles of $\mathrm{BSA}$ in $\mathrm{D}_{2} \mathrm{O}$ without $\mathrm{HauCl}_{4}$. The changes in the domains' arrangement were similar in normal and heavy water. The results presented in Figure 7 show that the relative position of domain I and II at pD 12 changes significantly compared with pure BSA at $\mathrm{pD} 7$. On the other hand, adjusting the BSA-Au system's $\mathrm{pD}$ value to $\sim 7$, and increasing the angles of two adjacent domains, similar to 
an opening, is further enhanced. No clear trend was observed in the relative positions of domains II, III, and IV. These results suggest that the domain rich in $\mathrm{Au}$ (III) (or Au) is localized between domains I and II. This finding is in good agreement with the recently published work of Dixon et al., who claimed that the fluorophore is located on the fragment of protein from residue 115-312 (almost perfectly covered by domain II in our case) based on proteolysis of the BSA-gold conjugate.
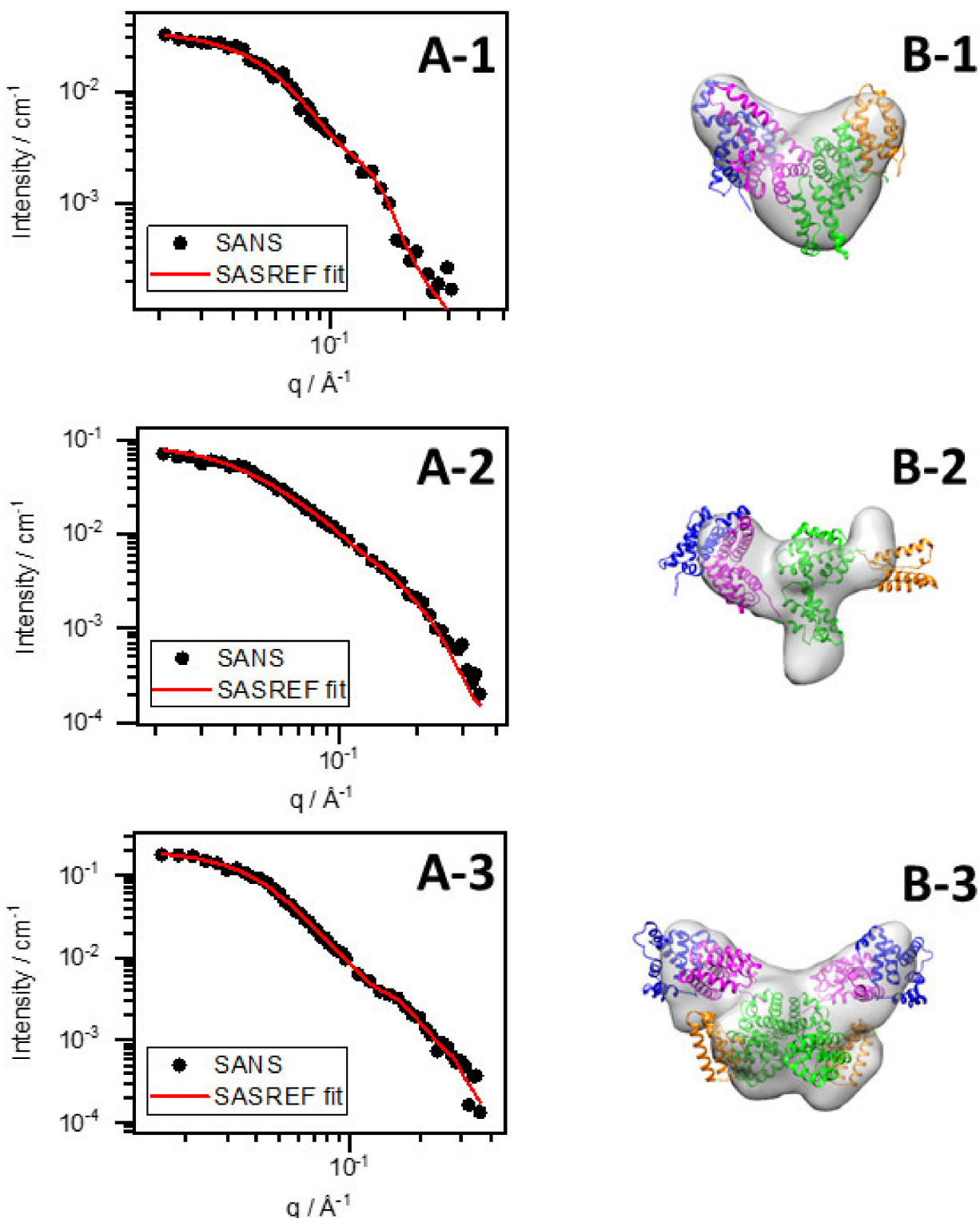

B-3

Figure 5. SANS curve of native BSA at $\mathrm{pD} \sim 7$ and SASREF fit (A-1), SANS curve of BSA-Au conjugates at $\mathrm{pD} \sim 12$ and SASREF fit (A-2), SANS curve of BSA-Au at $\mathrm{pD} \sim 7$ and SASREF fit (A-3), obtained SASREF (cartoon) and DAMMIF (surface) structures (B-1-B-3). 

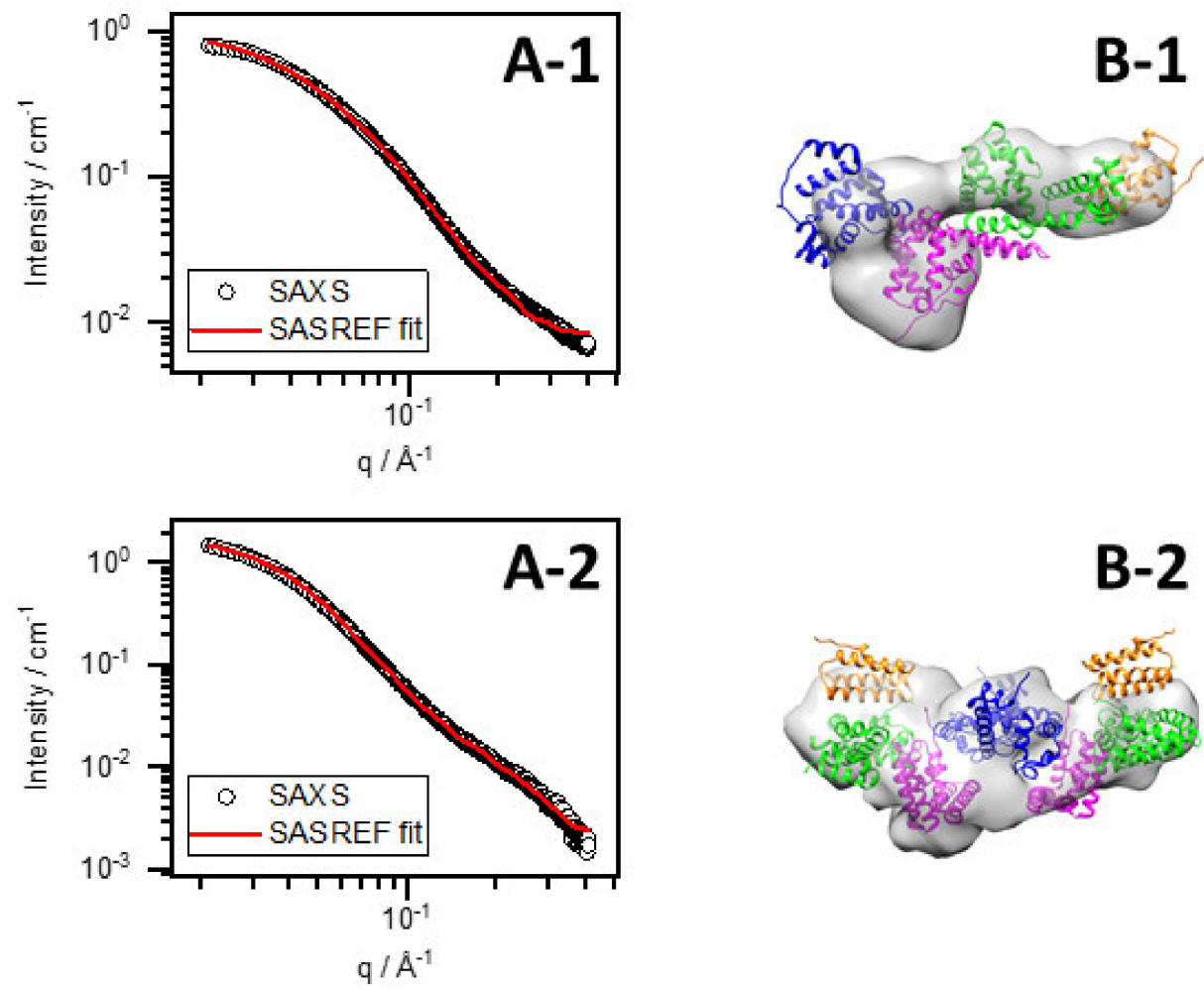

Figure 6. SAXS curve of BSA-Au conjugates at $\mathrm{pD} \sim 12$ and SASREF fit (A-1), SAXS curve of BSAAu conjugates at $\mathrm{pD} \sim 7$ and SASREF fit (A-2), obtained SASREF (cartoon) and DAMMIF (surface) structures (B-1,B-2).
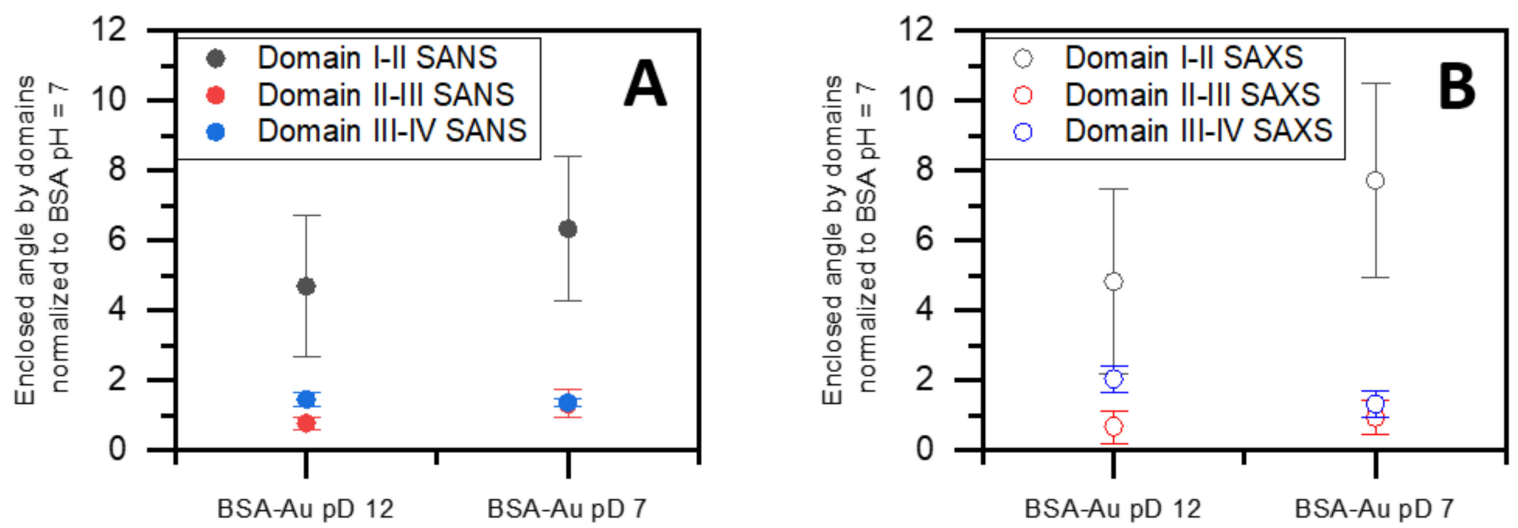

Figure 7. Enclosed angle by domain I-II, II-III, and III-IV obtained by SASREF from SANS (A) and SAXS (B) curves.

\subsection{Dynamic Light Scattering}

Apart from some methodological uncertainties and unknown diluting effects inevitable by measuring, dynamic light scattering also shows differences in the solvation effect between normal and heavy water. Although the BSA parent system is not the main subject of our present work, it is reasonable to recall its apparent size difference in the two solvents. In normal water, native BSA shows a small mean hydrodynamic diameter (approx. $37 \AA$ ) at $\mathrm{pH}=7$, extending to a significantly larger value (approx. $99 \AA$ ) at $\mathrm{pH}=12$ due to unfolding. These diameters show similar values in heavy water (38 and $81 \AA$, respectively). In the presence of $\mathrm{Au}(\mathrm{III})$ ions in water, the characteristic value decreases from $131 \AA$ to $115 \AA$ if the $\mathrm{pH}$ value changes from 12 to 7 . Hydrodynamic diameters show drastically different tendencies in heavy water as the value increases from $126 \AA$ to $233 \AA$ upon neutralization (Table 4 ). We observed that the latter value was practically halved 
(119 ̊ with 70.7\% polydispersity) after a mild ultrasonic treatment, indicating the existence of BSA-Au conjugate dimers which can fall apart in the $\mathrm{D}_{2} \mathrm{O}$ matrix.

Table 4. Hydrodynamic radius of the BSA-Au and BSA systems in $\mathrm{H}_{2} \mathrm{O}$ and $\mathrm{D}_{2} \mathrm{O}$ at given $\mathrm{pH}(\mathrm{pD})$ values. The polydispersity index is also given in $\%$.

\begin{tabular}{ccccccccc}
\hline & $\begin{array}{c}\text { BSA } \\
\text { pH7 }\end{array}$ & $\begin{array}{c}\text { BSA } \\
\text { pH12 }\end{array}$ & $\begin{array}{c}\text { BSA-Au } \\
\text { pH12 }\end{array}$ & $\begin{array}{c}\text { BSA-Au } \\
\text { pH7 }\end{array}$ & $\begin{array}{c}\text { BSA } \\
\text { pD7 }\end{array}$ & $\begin{array}{c}\text { BSA } \\
\text { pD12 }\end{array}$ & $\begin{array}{c}\text { BSA-Au } \\
\text { pD12 }\end{array}$ & $\begin{array}{c}\text { BSA-Au } \\
\text { pD7 }\end{array}$ \\
\hline Diameter, $\mathrm{D}_{\mathrm{h}}(\AA)$ & 37 & 99 & 131 & 115 & 38 & 81 & 126 & $233 / 119 *$ \\
Polydisp. (\%) & 57.7 & 16.7 & 23.8 & 27.5 & 41.0 & 19.9 & 21.5 & $15.9 / 70.7 *$ \\
\hline * after ultrasonic treatment. & & & & & & &
\end{tabular}

Besides the good agreement with model calculations (presented in Figures 5 and 6), comparing radii of gyration to the mean hydrodynamic diameters also provides the same conclusion. One must consider that SAXS and SANS measure the "compact cores" of conjugates uninfluenced by the hydration layer. Radii of gyration increased by about $40 \%$ after neutralization in $\mathrm{D}_{2} \mathrm{O}$ (Table 4 ). A decrease was observed in a previous study from $44.7 \AA$ to $37.5 \AA$ in $\mathrm{H}_{2} \mathrm{O}$, which aligns with our present DLS data and strengthens the fact that dimerization does not occur in the normal water system. The fluorescence measurements met this finding since the red emission spectrum in the $\mathrm{D}_{2} \mathrm{O}$ system is wider than that in $\mathrm{H}_{2} \mathrm{O}$, emphasizing structural differences in the two systems. Supposedly, the extended dimer conjugates contribute to energy transfer mechanisms and, finally, increase the quantum yield in heavy water.

\section{Conclusions}

Our experimental studies revealed that red fluorescence's evolution is not exclusively related to protein-gold interactions and is strongly influenced by hydration effects. The perturbation differences in hydration processes induced by the hydrogen-deuterium isotope effect were revealed by fluorescence and infrared spectroscopies. The fine structural changes observed were manifested in the luminescence behavior. Since the conformation of the protein is highly affected by the (actual) $\mathrm{H}(\mathrm{D})$-bond network, the medium appears to play an important role in the conformation-related optical properties. Indeed, the fluorescence quantum yield of the BSA-Au conjugates in heavy water increased significantly $(50 \%)$ compared with normal water-containing matrix. Collaterally, the alterations of fine atomic structures observed with IR spectroscopy are in rapport with the conformational changes appearing at significantly larger dimensions. The use of a single rigid-body model is admittedly a crude one; however, the changes in the scattering curves induced by choice of medium $\left(\mathrm{H}_{2} \mathrm{O}\right.$ or $\left.\mathrm{D}_{2} \mathrm{O}\right)$, as well as the $\mathrm{pH}($ or $\mathrm{pD})$, were found to be much larger than the effects of conformational dynamics of the protein, justifying the use of a single, representative conformational model for the dynamic ensemble in all cases [31].

The choice of medium slightly affects the overall protein conformation. The trend of domain motion upon adjusting the $\mathrm{pH}$ in alkaline and neutral intervals is the same in both water systems, with only the first two domains affected by the interaction with $\mathrm{Au}$. Dimer formation in BSA-gold conjugates at $\mathrm{pH}=7$ and even $\mathrm{pD} \sim 7$ was observed with scattering techniques. The connected fine structural, configurational, and optical features may indicate that the developed BSA-gold ion bioconjugates (sensitive to several kinds of external perturbations) are similar to associates of polyelectrolyte and gold ions, rather than "robust" compact nanoclusters attached to the BSA protein. The versatility of the occurring energy transfer in these associates may explain the observed complex luminescence features.

Author Contributions: Conceptualization: A.B., B.F.; methodology: B.F., A.B., J.M., A.D., L.A., A.W., Z.V., J.S.P.; software: B.F., A.W., J.S.P.; validation: A.W., B.F., A.D., Z.V.; formal analysis: B.F., J.M, A.W., J.S.P.; investigations: A.B., J.M., B.F., A.D.; data curation: A.B., A.W.; writing-original draft preparation: A.B., B.F.; writing-review and editing: A.W., A.D., J.M.; visualization: B.F., J.M., A.B.; 
supervision: A.B.; project administration: A.B., I.V., funding acquisition: A.B., J.M., Z.V., B.F., L.A. All authors have read and agreed to the published version of the manuscript.

Funding: This research was funded by the National Research, Development and Innovation Office Hungary under grants K131657 (A. Bóta) and K131594 (J. Mihály) and also by Project no. 2018-1.2.1NKP-2018-00005 under the 2018-1.2.1-NKP funding scheme (A. Bóta, Z. Varga).

Data Availability Statement: Processed and derived data are available from the first author B.F. on request.

Acknowledgments: We would like to acknowledge the protein research program of the Hungarian Academy of Sciences (MEDinPROT, A. Bóta), and [KIFÜ] for awarding us access to resources based in Hungary at Debrecen for PPU time.

Conflicts of Interest: The authors declare no conflict of interest.

\section{References}

1. Peng, H.-S.; Chiu, D.T. Soft fluorescent nanomaterials for biological and biomedical imaging. Chem. Soc. Rev. 2015, 44, 4699-4722. [CrossRef] [PubMed]

2. Xie, J.; Zheng, Y.; Ying, J.Y. Protein-directed synthesis of highly fluorescent gold nanoclusters. J. Am. Chem. Soc. 2009, 131, 888-889. [CrossRef] [PubMed]

3. Wu, Z.; Jin, R. On the ligand's role in the fluorescence of gold nanoclusters. Nano Lett. 2010, 10, 2568-2573. [CrossRef] [PubMed]

4. Wen, X.; Yu, P.; Toh, Y.-R.; Tang, J. Structure-correlated dual fluorescent bands in BSA-protected Au 25 nanoclusters. J. Phys. Chem. C 2012, 116, 11830-11836. [CrossRef]

5. Mohanty, J.S.; Chaudhari, K.; Sudhakar, C.; Pradeep, T. Metal-ion-induced luminescence enhancement in protein protected gold clusters. J. Phys. Chem. C 2019, 123, 28969-28976. [CrossRef]

6. Le Guével, X.; Hötzer, B.; Jung, G.; Hollemeyer, K.; Trouillet, V.; Schneider, M. Formation of fluorescent metal (Au, Ag) nanoclusters capped in bovine serum albumin followed by fluorescence and spectroscopy. J. Phys. Chem. C 2011, 115, 10955-10963. [CrossRef]

7. Chaudhari, K.; Xavier, P.L.; Pradeep, T. Understanding the evolution of luminescent gold quantum clusters in protein templates. ACS Nano 2011, 5, 8816-8827. [CrossRef]

8. Sadler, P.J.; Tucker, A. PH-induced structural transitions of bovine serum albumin. Histidine PKa values and unfolding of the N-terminus during the $\mathrm{N}$ to $\mathrm{F}$ transition. Eur. J. Biochem. 1993, 212, 811-817. [CrossRef]

9. Lin, H.; Imakita, K.; Fujii, M.; Sun, C.; Chen, B.; Kanno, T.; Sugimoto, H. New insights into the red luminescent bovine serum albumin conjugated gold nanospecies. J. Alloys Compd. 2017, 691, 860-865. [CrossRef]

10. Dixon, J.M.; Egusa, S. Conformational change-induced fluorescence of bovine serum albumin-gold complexes. J. Am. Chem. Soc. 2018, 140, 2265-2271. [CrossRef]

11. Dixon, J.M.; Tomida, J.; Egusa, S. Identifying the red-luminophore-forming domain in serum albumin-gold complexes. J. Phys. Chem. Lett. 2020, 11, 3345-3349. [CrossRef]

12. Fehér, B.; Lyngsø, J.; Bartók, B.; Mihály, J.; Varga, Z.; Mészáros, R.; Pedersen, J.S.; Bóta, A.; Varga, I. Effect of PH on the conformation of bovine serume albumin-gold bioconjugates. J. Mol. Liq. 2020, 309, 113065. [CrossRef]

13. Grdadolnik, J.; Maréchal, Y. Hydrogen-deuterium exchange in bovine serum albumin protein monitored by fourier transform infrared spectroscopy, Part I: Structural studies. Appl. Spectrosc. 2005, 59, 1347-1356. [CrossRef]

14. Reslan, M.; Kayser, V. The effect of deuterium oxide on the conformational stability and aggregation of bovine serum albumin. Pharm. Dev. Technol. 2018, 23, 1030-1036. [CrossRef]

15. Gardecki, J.A.; Maroncelli, M. Set of secondary emission standards for calibration of the spectral responsivity in emission spectroscopy. Appl. Spectrosc. 1998, 52, 1179-1189. [CrossRef]

16. Crosby, G.A.; Demas, J.N. Measurement of photoluminescence quantum yields. Review. J. Phys. Chem. 1971, 75, 991-1024. [CrossRef]

17. Varga, Z.; Mihály, J.; Berényi, S.; Bóta, A. Structural characterization of the poly(ethylene glycol) layer of sterically stabilized liposomes by means of FTIR spectroscopy. Eur. Polym. J. 2013, 49, 2415-2421. [CrossRef]

18. CENIMAT. Dynamic Light Scattering (DLS)—AvidNano W130i. Available online: https:/ /www.cenimat.fct.unl.pt/services/ laboratory-electronic-and-optoelectronic-materials-and-devices / dynamic-light-scattering-dls-avidnano-w130i (accessed on 9 December 2021).

19. Wacha, A.; Varga, Z.; Bóta, A. CREDO: A new general-purpose laboratory instrument for small-angle X-ray scattering. J. Appl. Cryst. 2014, 47, 1749-1754. [CrossRef]

20. Wacha, A. Optimized pinhole geometry for small-angle scattering. J. Appl. Cryst. 2015, 48, 1843-1848. [CrossRef]

21. SANS. Budapest Neutron Centre. Available online: https://www.bnc.hu/?q=ys-sans (accessed on 19 December 2021).

22. Almásy, L. New measurement control software on the yellow submarine SANS instrument at the Budapest Neutron Centre. J. Surf. Investig. X-ray Synchrotron Neutron Tech. 2021, 15, 527-531. [CrossRef]

23. Barth, A. Infrared spectroscopy of proteins. Biochim. Biophys. Acta-Bioenerg. 2007, 1767, 1073-1101. [CrossRef] [PubMed] 
24. Lu, R.; Li, W.-W.; Katzir, A.; Raichlin, Y.; Yu, H.-Q.; Mizaikoff, B. Probing the secondary structure of bovine serum albumin during heat-induced denaturation using mid-infrared fiberoptic sensors. Analyst 2015, 140, 765-770. [CrossRef] [PubMed]

25. Glatter, O. A new method for the evaluation of small-angle scattering data. J. Appl. Cryst. 1977, 10, 415-421. [CrossRef]

26. Svergun, D.I. Determination of the regularization parameter in indirect-transform methods using perceptual criteria. J. Appl. Cryst. 1992, 25, 495-503. [CrossRef]

27. Jeffries, C.M.; Graewert, M.A.; Blanchet, C.E.; Langley, D.B.; Whitten, A.E.; Svergun, D.I. Preparing monodisperse macromolecular samples for successful biological small-angle X-ray and neutron-scattering experiments. Nat. Protoc. 2016, 11, $2122-2153$. [CrossRef] [PubMed]

28. Franke, D.; Svergun, D.I. DAMMIF, a program for rapid ab-initio shape determination in small-angle scattering. J. Appl. Crystallogr. 2009, 42, 342-346. [CrossRef]

29. Petoukhov, M.V.; Svergun, D.I. Global rigid body modeling of macromolecular complexes against small-angle scattering data. Biophys. J. 2005, 89, 1237-1250. [CrossRef]

30. Volkov, V.V.; Svergun, D.I. Uniqueness of ab initio shape determination in small-angle scattering. J. Appl. Cryst. 2003, 36, 860-864. [CrossRef]

31. Tria, G.; Mertens, H.D.T.; Kachala, M.; Svergun, D.I. Advanced ensemble modelling of flexible macromolecules using X-ray solution scattering. IUCrJ 2015, 2, 207-217. [CrossRef] 